\title{
Demo and Curve Drawing Model of Relationship between Tangent and Cotangent Function with Varying Period Amplitude
}

\author{
Shuying Wang ${ }^{1, a}$, Zhanmin Yang ${ }^{2, b}$, Yi Wang ${ }^{3, c}$ \\ ${ }^{1,2}$ Nanjing Institute of Industry Technology, China \\ ${ }^{3}$ School of computer science and technology, Nanjing University of Science and Technology, \\ China \\ ªwangsy@niit.edu.cn, byangzm@niit.edu.cn, 893762530@qq.com
}

\begin{abstract}
Keywords: tangent function. arc expansion. displacement mapping. function demonstration. curve Abstract. In accordance with the principle of arc expansion and the displacement of projection, the demo and curve model of relationship between tangent and cotangent function shall be designed and drawn. The paper introduces the composition structure of the model, analyzes the main parameters of the system and describes the working principle of the system so as to illustrate the specific application of the model on the basis of the different periods and amplitudes.
\end{abstract}

\section{Introduction.}

Function image is regarded as the geometry representation of function in the rectangular coordinate system. For unary monotonic function, its image is usually a plane curve, and a clear and accurate curve will bring great convenience to study the function. So, using dynamic form to demonstrate function relations can impress the learners deeply with curve drawing, thus helping us learn and research function. In functions, it is a bit difficult to demonstrate tangent and cotangent function and their generic forms, and draw their curves because the demonstration and curve not only reflects the right angle corresponding relationship between angle and function value but also indicates the different effects caused by other factors, such as initial phase, period and amplitude. An entity model is designed and made as demonstrating and drawing. That is, based on trigonometric definition, the increase of arc length is rotated into linear expansion by mechanical means and the parallel and independent movement of vertical rods is used to conduct displacement mapping of function value so as to project the circular motion of dot on the plane as orthogonal synthetic movement of the dot in rectangular coordinate system. And its trajectory entails function curve. At this stage, such methods as drawing dots and computer software assignment are taken to draw ${ }^{[1,2]}$. Selecting dots is complicated and the calculating results are mainly approximations with broken lines as the connecting lines among fixed dots with the result that the curve full picture cannot be seen. So, drawing is inefficient with poor applicability. The paper aims to design the tangent (cotangent) function curve tracer on the basis of arc development and isometric transformation principle ${ }^{[2,3]}$. By setting the initial state of the model, as long as the handle of the driving wheel is shaken, a coherent and complete standard function curve shall be drawn on paper or drawing board. The image of simple function $y=\tan x, y=\cot x \operatorname{can}$ be drawn and that of complicated function $y=\tan (x+\varphi), y=a \tan x$ drawn. Model curve drawing process directly reflects the formation process of the function. Try the models with different specifications so as to draw large-scale curves on the classroom blackboard, draw miniature curves on students' exercise books, and even draw practical curves in line with the requirement of engineering and technology. The device can be used as teaching aids or drawing tools for teaching and engineering.

\section{Circular movement and displacement mapping.}

In circular movement, $\mathrm{O}_{1} x_{1} y_{1}$ in rectangular coordinate system (Figure 1.), supposed that the moving point rotates around fixed one $\mathrm{O}_{1}$ to do circular movement, the trajectory equation is $\boldsymbol{x}_{1}^{2}+\boldsymbol{y}_{1}^{2}=1$. Among them, unit circle is denoted as $\odot \mathrm{O}_{1} . \mathrm{S}_{1}$ and $\mathrm{C}_{1}$ are two points on the circumference. 
Given $\mathrm{O}_{1} S_{1} \perp \mathrm{O}_{1} C_{1}$, the rays through radius are $\mathrm{O}_{1} \mathrm{Q}_{1}$ and $\mathrm{O}_{1} \mathrm{Q}_{2}$ respectively. The intersections between $\odot \mathrm{O}_{1}$ and axis $\mathrm{O}_{1} x_{1}$ are $\mathrm{A}_{1}$ and $\mathrm{A}_{2}$. The lines, through $\mathrm{A}_{1}$ and $\mathrm{A}_{2}$, which are perpendicular to the axis $\mathrm{O}_{1} x_{1}$, are $A_{1} B_{1}$ and $A_{2} B_{2}$. And the intersections between $O_{1} Q_{1}$ and $A_{1} B_{1}, O_{1} Q_{2}$ and tangent $A_{2} B_{2}$ of $\odot O_{1}$ are respectively $\mathrm{A}_{1}$ and $\mathrm{A}_{2}$. If $\angle A_{1} \mathrm{O}_{1} S_{1}=x$, the length of arc is $x$. So, there are $A_{1} T_{1}=\tan x$ and $A_{2} M_{1}=\cot x$ according to the definition of trigonometric function.

Projection trajectory. once rectangular coordinate system oxy (Figure 1) is set, whose unit is same as $\mathrm{O}_{1} x_{1} y_{1}$, the axes of $\mathrm{O}^{+}$and $\mathrm{O}_{1} y_{1}^{+}$are in the same direction with $\mathrm{O}^{+}$and $\mathrm{O}_{1} x_{1}^{+}$overlap and $\left|A_{1} O\right|_{\geq \pi}$. $\mathrm{A}_{1}$ of the circumference $\odot \mathrm{O}_{1}$ is correspondingly fixed on the origin point $\mathrm{O}$ and the arc $A_{1} S_{1}$ is straightened along axis $\mathrm{O} x$. The point corresponding to $\mathrm{S}_{1}$ is $X$, that is $O X=x$. When $\mathrm{S}_{1}$ moves from point $\mathrm{A}_{1}$ counterclockwise, $A_{1} S_{1}$ straightens along the axis of $O x^{+}$, that is $O X=x \geq 0$. When $\mathrm{S}_{1}$ moves clockwise, $A_{1} S_{1}$ straightens along the axis of $O x^{-}$, that is $O X=x \leq 0$. The line $O X=x \leq 0$ through point $\mathrm{X}$ is perpendicular to the axis $\mathrm{O} x$ and the projection of point $\mathrm{T}_{1}$ and $\mathrm{M}_{1}$ on the $X Q$ is $T$ and $\mathrm{M}$ respectively. So, $X T=A_{1} T_{1}$ and $X M=A_{2} M_{1}$. When $\mathrm{S}_{1}$ does circular motion on $\odot \mathrm{O}_{1}$, the trajectory equations of projection point $\mathrm{T}$ and $\mathrm{M}$ are as follows, $y=X T=\tan x, y=X M=\cot x .^{[4,5]}$

The projection $X T$ and $X M$ of displacement vector $\overrightarrow{A_{1} T_{1}}$ and $\overrightarrow{A_{2} M_{1}}$ from moving points $T_{1}$ and $M_{1}$ to axis $\mathrm{O}_{1} x_{1}$ on moving vector $\overrightarrow{X Q}$ is named as a displacement map.

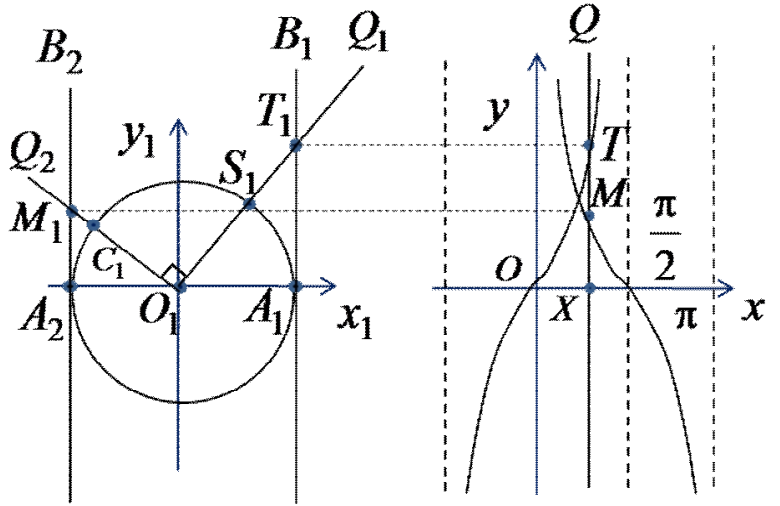

Fig.1.Circular arc projection point trajectory.

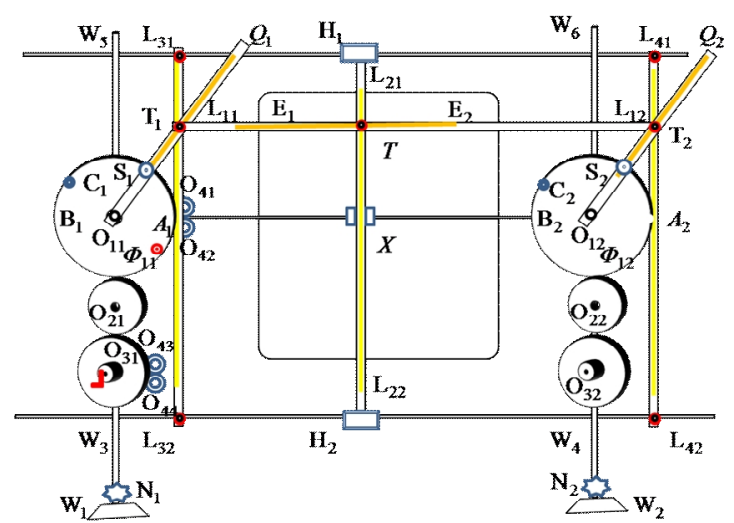

Fig.2. Tangent curve plotting model structure

\section{Circular movement and displacement mapping.}

According to the circular linear expansion and displacement mapping principle, a system model can be constructed to express the movement of each point. The model consists of a bracket, spinning wheel disc, driving wheel disc, driving gear, chute dowel lever, brush and link, etc., as shown in Figure 2.

Support. Bracket is composed of anchors $\mathrm{W}_{1}$ and $\mathrm{W}_{2}$, vertical rods $\mathrm{W}_{3} \mathrm{~W}_{5}$ and $\mathrm{W}_{4} \mathrm{~W}_{6}$ and lateral poles $\mathrm{W}_{3} \mathrm{~W}_{4}$ and $\mathrm{W}_{5} \mathrm{~W}_{6}$, etc. And there are spinning wheels $\mathrm{N}_{1}$ and $\mathrm{N}_{2}$ between the anchor and vertical rod. And there are vertical shafts $\mathrm{O}_{11} \mathrm{Z}$ and $\mathrm{O}_{12} \mathrm{Z}$ on the points of $\mathrm{O}_{11}$ and $\mathrm{O}_{12}$ of vertical rods $\mathrm{W}_{3} \mathrm{~W}_{5}$ and $\mathrm{W}_{4} \mathrm{~W}_{6}$. With the middle of vertical rods $\mathrm{W}_{3} \mathrm{~W}_{4}$ and $\mathrm{W}_{5} \mathrm{~W}_{6}$, on it, there are sliders $\mathrm{H}_{1}$ and $\mathrm{H}_{2}$ and a flat panel $\mathrm{E}_{1} \mathrm{E}_{2}$ between $\mathrm{W}_{3} \mathrm{~W}_{4}$ and $\mathrm{W}_{5} \mathrm{~W}_{6}$ is equipped.

Spinning wheel disc. the disc of the same radius $\mathrm{R}$ is superimposed on circular gear to form it. They have a unified central shaft hole and there is a circle of bolt holes on the front side of the outer edge of the disk plane. The wheel discs, which are equipped on the shafts $\mathrm{O}_{11} \mathrm{z}$ and $\mathrm{O}_{12} \mathrm{z}$, are denoted as $\odot \mathrm{O}_{11}$ and $\odot \mathrm{O}_{12}$, which are identical in size and shape. The bolt holes on the disc plane $\odot \mathrm{O}_{11}$ are denoted as $\mathrm{S}_{1}, \mathrm{C}_{1}$ and those on the $\Phi_{11}$ as $\mathrm{S}_{2}, \mathrm{C}_{2}$ and $\Phi_{12}$. Among them, $\mathrm{O}_{11} \mathrm{~S}_{1} \perp \mathrm{O}_{11} \mathrm{C}_{1}, \mathrm{O}_{12} \mathrm{~S}_{2} \perp \mathrm{O}_{12} \mathrm{C}_{2}$, the radius is $\mathrm{R}$ from bolt hole center to the center of the wheel disk. 
Driving wheel disc. a large gear is superimposed on the disc and pinion. And pinion is rectangular alveolus with the disc in the middle of two gears, whose radius is same as that of the large gear. And the large gear can mesh with the circular gear of spinning wheel. Circular disc and large gear and pinion are fixed together to share a shaft, one end of which can be installed anywhere in the bracket and the other end of which can insert into the spinning handle. According to the radius difference of large gears, there are many different variety of models, among which the two driving wheel discs with radius as $0.5 \mathrm{R}$ are denoted as $\odot \mathrm{O}_{21}$ and $\odot \mathrm{O}_{22}$, and those with radius as $2 \mathrm{R}$ as $\odot \mathrm{O}_{23}$ and $\odot \mathrm{O}_{24}$. The pinions are same so they can be connected through rectangular toothed belts.

Driving gear is a circular one with a smaller radius, which functions as coordinating that the turning of the driving wheel disc and spinning one is consistent, and its gears can mesh with those on spinning wheel disc and the teeth on large gears. Those, which are fixed on brace $\mathrm{W}_{3} \mathrm{~W}_{5}$ and $\mathrm{W}_{4} \mathrm{~W}_{6}$, are denoted as driving wheel $\odot \mathrm{O}_{41}$ and $\odot \mathrm{O}_{42}$.

Chute dowel lever is a long pole with rectangular cross section and the middle is vacant with the chute in the inner edge. There are three levers which is vertical to axis $\mathrm{O}_{11} \mathrm{O}_{12}$, two ends of which with clamps can be fixed on the lateral poles $\mathrm{W}_{3} \mathrm{~W}_{4}$ and $\mathrm{W}_{5} \mathrm{~W}_{6}$, which are denoted as $\mathrm{L}_{31} \mathrm{~L}_{32}$ and $\mathrm{L}_{41} \mathrm{~L}_{42}$ respectively. The two ends of the levers which connect with sliders $\mathrm{H}_{1}$ and $\mathrm{H}_{2}$ are vertical chute dowel lever, which are denoted as $\mathrm{L}_{21} \mathrm{~L}_{22}$ or $\mathrm{H}_{1} \mathrm{H}_{2}$. Its intersection with $\mathrm{O}_{11} \mathrm{O}_{12}$ is denoted as $\mathrm{X}$. There is a blank respectively on the frame corresponding to $\mathrm{X}$, among which, the one close to $\mathrm{O}_{11}$ is denoted as $\mathrm{X}_{11}$ and the other as $\mathrm{X}_{12}$. That level, parallel to the axis $\mathrm{O}_{11} \mathrm{O}_{12}$, is lateral chute dowel one as $\mathrm{L}_{11} \mathrm{~L}_{12}$, two ends of which are connected with the sliders in chute dowel levers $\mathrm{L}_{31} \mathrm{~L}_{32}, \mathrm{~L}_{41} \mathrm{~L}_{42}$. The levers which are fixed on the radius of spinning gears $\odot \mathrm{O}_{11}$ and $\odot \mathrm{O}_{12}$ are radial chute dowel levers as $\mathrm{O}_{11} \mathrm{Q}_{1}$ and $\mathrm{O}_{12} \mathrm{Q}_{2}$. They are same in size and shape with the length larger than the radius of driving wheel disc.

Slider is a rectangular object, which is embedded in the chute of chute dowel lever. There is a shaft hole in the middle of each chute. The sliders of chute dowel levers $\mathrm{L}_{11} \mathrm{~L}_{12}$ and $\mathrm{L}_{21} \mathrm{~L}_{22}$ are denoted as $\mathrm{K}_{11}$ and $\mathrm{K}_{21}$, which are connected through shaft $\mathrm{T}$. The sliders of chute dowel levers $\mathrm{L}_{31} \mathrm{~L}_{32}$ and $\mathrm{O}_{11} \mathrm{Q}_{1}$ are denoted as $\mathrm{K}_{12}$ and $\mathrm{K}_{22}$, which are connected through pin shaft $\mathrm{T}_{1}$. And the sliders of chute dowel levers $\mathrm{L}_{41} \mathrm{~L}_{42}$ and $\mathrm{O}_{12} \mathrm{Q}_{2}$ are denoted as $\mathrm{K}_{13}$ and $\mathrm{K}_{23}$, which are connected through pin shaft $\mathrm{T}_{2}$.

Brush is a conical object whose nib is set at the top of the cone so as to draw traces of color in contact with such planes as paper or drawing board. The rack is set at the bottom of the cone, which can be directly inserted into the shaft hole. The bush installed on the shaft $\mathrm{T}$ is denoted as brush $\mathrm{Y}$.

Pulley. a pair of externally tangent fixed pulley is fixed on the $-f$ frame vertical pole with externally tangent point at the intersection of lateral and vertical pole. On the lateral pole, movable clamp is mounted so as to fix externally tangent pulley on any position of the bracket. The pulley mounted at $\mathrm{R}$ of center line $\mathrm{O}_{11} \mathrm{O}_{12}$ is denoted as $\odot \mathrm{O}_{41}, \odot \mathrm{O}_{42}$ and the pulley mounted on the center line $\mathrm{O}_{21} \mathrm{O}_{22}$ as $\odot \mathrm{O}_{43}$ and $\odot \mathrm{O}_{44}$.

Link is a soft inelastic rope for pulling lever $\mathrm{H}_{1} \mathrm{H}_{2}$ to slide crosswise, whose top is fixed on the cylindrical surface of the disc and whose end is fixed at the $\mathrm{X}$ of pole $\mathrm{H}_{1} \mathrm{H}_{2}$ through the pulley $\odot \mathrm{O}_{32}$ and $\odot \mathrm{O}_{31}$.

\section{Working principle of the model.}

Initial state setting: to adjust the spinning wheel $\mathrm{N}_{1} \mathrm{~N}_{2}$ of the bracket anchor so as to make the shaft $\mathrm{O}_{11} \mathrm{O}_{12}$ of spinning disc at the horizontal state. On the drawing board $\mathrm{E}_{1} \mathrm{E}_{2}$, rectangular coordinate system $\mathrm{O} x y$ is drawn, among which, the axis $\mathrm{O} x^{+}$overlaps $\mathrm{O}_{11} \mathrm{O}_{12}$ and the axis $\mathrm{O} y$ is parallel to the pole $\mathrm{H}_{1} \mathrm{H}_{2}$. The distance from $\mathrm{L}_{31} \mathrm{~L}_{32}$ and $\mathrm{L}_{41} \mathrm{~L}_{42}$ to the center of $\operatorname{disc} \odot \mathrm{O}_{11}$ and $\odot \mathrm{O}_{12}$ is same, at the same side of vertical pole $\mathrm{W}_{3} \mathrm{~W}_{5}$ and $\mathrm{W}_{4} \mathrm{~W}_{6}$. the lateral displacement of the point of slider bar $\mathrm{L}_{21} \mathrm{~L}_{22}$ on the axis $\mathrm{O} y$ is denoted as $x$ and the vertical displacement of the point of slider bar $\mathrm{L}_{11} \mathrm{~L}_{12}$ on the axis $\mathrm{O} x$ as $y$. The initial positions before the $\operatorname{discs} \odot \mathrm{O}_{11}$ and $\odot \mathrm{O}_{12}$ rotate are set as $\mathrm{O}_{11} \mathrm{~A}_{1}$ and $\mathrm{O}_{12} \mathrm{~A}_{2}$ with the overlap of the point $\mathrm{A}_{1}$ on the disc $\odot \mathrm{O}_{11}$ and the tangent point of pulley of $\odot \mathrm{O}_{31}$ and $\odot \mathrm{O}_{32}$. The circuitous direction of the link is set so when the top of the link rotates clockwise on the disc with the value of the 
angle $\angle S_{1} \mathrm{O}_{11} A_{1}=x$ negative, the end of the link is fixed at $\mathrm{X}_{11}$ with the expansion point $\mathrm{X}$ of arc moving to the left horizontally along $\mathrm{O} x^{-}$. When the top of the link rotates counterclockwise with the value of the angle $\angle S_{1} \mathrm{O}_{11} A_{1}=x$ positive, the end of the link bypasses revolving shaft and is fixed at $\mathrm{X}_{12}$ with the expansion point $\mathrm{X}$ of arc moving to the right horizontally along $\mathrm{Ox}^{+}$.

Model job requirements: when the system is working, the spinning wheel discs $\odot \mathrm{O}_{11}$ and $\odot \mathrm{O}_{12}$ keep synchronous motion, namely their angular velocity is same with the slider of each pole can move freely so as to make pole $\mathrm{L}_{11} \mathrm{~L}_{12}$ parallel to axis $\mathrm{O} x$ and pole $\mathrm{L}_{21} \mathrm{~L}_{22}$ to axis $\mathrm{O} y$.

The variables operation in the model perform as follows: rotating disc is denoted as a unit circle and unit arc length and the number of central Angle radian are same. Then the link winding up the disc directly reflect the changes in the angle, namely the angle is converted into horizontal displacement through the arc length. And the link pulls in equal length to make pole $\mathrm{H}_{1} \mathrm{H}_{2}$ move in parallel so the change of the arc length is converted into that of the straight line segment. Intuitively it is to make a horizontal displacement between point $\mathrm{X}$ and the origin $\mathrm{O}$. When wheel $\operatorname{disc} \odot \mathrm{O}_{11}$ rotates, angle change is, $\angle S_{1} \mathrm{O}_{11} A_{1}=A_{1} S_{1}=O X=x$. Because pole $\mathrm{L}_{21} \mathrm{~L}_{22}$ makes side-to-side movement and pole $\mathrm{L}_{11} \mathrm{~L}_{12}$ moves up and down, the intersection of two poles is the synthesis of two orthogonal motion, which can be reflected through the brush Y sliding on the oxy. In this way, the side of the triangle is converted into longitudinal displacement by parallel bar, expressed with the function $y=f(x)$.

Limit state in the system: due to the limit by the length of longitudinal and radial poles, the system model can be drawn only with limited curve, for example, the curve at the side of Angle of $x= \pm \pi / 2$ in the limit state, the reason is that when radial pole rotates nearly parallel to longitudinal pole, their intersection point tends to be infinite.

\section{The working process of the system.}

Function $y=\tan x,(-\pi / 2<x<\pi / 2)$ image. As shown in Figure 3, by adjusting the spinning wheel $\mathrm{N}_{1} \mathrm{~N}_{2}$ of the anchor, disc axis $\mathrm{O}_{11} \mathrm{O}_{12}$ is in a level state. In the middle of the drawing board $\mathrm{E}_{1} \mathrm{E}_{2}$ rectangular coordinate system $\mathrm{O} x y$ is drawn with axis $\mathrm{Ox}^{+}$and $\mathrm{O}_{11} \mathrm{O}_{12}$ overlap. Driving wheel discs $\odot \mathrm{O}_{21}$ and $\odot \mathrm{O}_{22}$ are mounted on poles $\mathrm{W}_{3} \mathrm{~W}_{5}$ and $\mathrm{W}_{4} \mathrm{~W}_{6}$ respectively to make them mesh with the external part of the gear spinning wheel disc $\odot \mathrm{O}_{41}$ and $\odot \mathrm{O}_{42}$ of gear meshing. And the gear belt is installed between $\odot \mathrm{O}_{21}$ and $\odot \mathrm{O}_{22}$ to make the wheel discs $\odot \mathrm{O}_{11}$ and $\odot \mathrm{O}_{12}$ become synchronous rotation system. Pulleys $\odot \mathrm{O}_{31}$ and $\odot \mathrm{O}_{32}$ are mounted on shaft $\mathrm{O}_{11} \mathrm{O}_{12}$ to make the tangent point at the circumference $\mathrm{A}_{1}$ of wheel disc $\odot \mathrm{O}_{11}$. The longitudinal poles $\mathrm{L}_{31} \mathrm{~L}_{32}$ and $\mathrm{L}_{41} \mathrm{~L}_{42}$ are fixed at the point $\mathrm{A}_{1}$ and $\mathrm{A}_{2}$ of the right side of the disc $\odot \mathrm{O}_{11}$ and $\odot \mathrm{O}_{12}$ to make it tangent with the disc. The radial poles $\mathrm{O}_{11} \mathrm{Q}_{1}$ and $\mathrm{O}_{12} \mathrm{Q}_{2}$ are fixed at the $\mathrm{O}_{11} \mathrm{~S}_{1}$ and $\mathrm{O}_{12} \mathrm{~S}_{2}$ of the radius of the disc $\odot \mathrm{O}_{11}$ and $\odot \mathrm{O}_{12}$ respectively to make them link with sliders with shafts $\mathrm{T}_{1}$ and $\mathrm{T}_{2}$. The two ends of pole $\mathrm{L}_{11} \mathrm{~L}_{12}$ are connected with shafts $\mathrm{T}_{1}$ and $T_{2}$ respectively to make the sliders $K_{11}$ and $K_{21}$ link together with shaft $T$. The top of the link $S_{1} A_{1} O_{12} X_{12}$ is fixed at cylinder $\mathrm{S}_{1}$ of $\odot \mathrm{O}_{11}$ and its end is fixed at $\mathrm{X}_{12}$ of pole $\mathrm{H}_{1} \mathrm{H}_{2}$ through pulley $\odot \mathrm{O}_{32}$ (initial point $\mathrm{A}_{1}$ ) bypassing a shaft $\mathrm{O}_{2} \mathrm{Z}$ with the pole $\mathrm{H}_{1} \mathrm{H}_{2}$ and the shaft oy on $\mathrm{E}_{1} \mathrm{E}_{2}$ overlap. Adjusting the wheel discs $\odot \mathrm{O}_{1}$ and $\odot \mathrm{O}_{2}$ is to make the points of $\mathrm{S}_{1}$ and $\mathrm{S}_{2}$ respectively coincide with the initial ones $\mathrm{A}_{1}$ and $\mathrm{A}_{2}$ with pole $\mathrm{L}_{11} \mathrm{~L}_{12}$ and shaft ${ }_{0 x}$ overlap and the tope of brush $\mathrm{Y}$ is fixed at the origin $\mathrm{O}$. Shaking the handles of the driving wheel disc $\odot \mathrm{O}_{21}$ counterclockwise is to drive wheel disc $\odot \mathrm{O}_{11}$ and $\odot \mathrm{O}_{12}$ move synchronically counterclockwise. The angle $\angle S_{1} \mathrm{O}_{11} A_{1}$ expands positively and one end of link $S_{1} A_{1} O_{12} X_{12}$ at the same part of $\mathrm{S}_{1}$ rotates with wheel disc $\odot \mathrm{O}_{11}$ with subsequent link winding on the

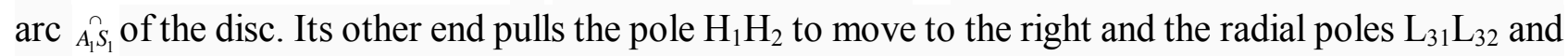
$\mathrm{L}_{41} \mathrm{~L}_{42}$ push the sliders $\mathrm{K}_{22}$ and $\mathrm{K}_{23}$ inside to move so sliders $\mathrm{K}_{22}$ and $\mathrm{K}_{23}$ drive the slider $\mathrm{K}_{12}$ and $\mathrm{K}_{13}$ through shafts $\mathrm{T}_{1}$ and $\mathrm{T}_{2}$ to move up in longitudinal poles $\mathrm{L}_{31} \mathrm{~L}_{32}$ and $\mathrm{L}_{41} \mathrm{~L}_{42}$. Poles $\mathrm{H}_{1} \mathrm{H}_{2}$ and $\mathrm{L}_{11} \mathrm{~L}_{12}$ drive brush $\mathrm{Y}$ to leave a mark on the drawing board $\mathrm{E}_{1} \mathrm{E}_{2}$, which is the image of function 
$f(x)=\tan x,(0 \leq x<\pi / 2)$. Afterwards, the system is reset to the initial state (brush Y stays in a state of origin at $\mathrm{O}$ and others keep on). Link $S_{1} A_{1} X_{11}$ is changed with its top still and its end connected directly with the $\mathrm{X}_{11}$ through pulley $\odot \mathrm{O}_{31}$. Shaking the handle of driving wheel disc $\odot \mathrm{O}_{21}$ clockwise is to drive the wheel discs $\odot \mathrm{O}_{11}$ and $\odot \mathrm{O}_{12}$ to rotate synchronously clockwise. The angle $\angle S_{1} \mathrm{O}_{11} A_{1}$ expands reversely. One end of link $S_{1} A_{1} X_{11}$ at the same part of $\mathrm{S}_{1}$ rotates with wheel disc $\odot \mathrm{O}_{11}$ with subsequent link winding on the arc ${ }_{A_{1} S_{1}}$ of the disc and its other end pulls the pole $\mathrm{H}_{1} \mathrm{H}_{2}$ to move to the left so brush $\mathrm{Y}$ can draw the curve on the drawing board $\mathrm{E}_{1} \mathrm{E}_{2}$ as the image of the function $f(x)=\tan x,(-\pi / 2<x<0)$. The above-mentioned two processes are combined to make the image of the function $y=\tan x,(-\pi / 2<x<\pi / 2)$.

Image of function. $y=\cot x,(0 \leq x \leq \pi)$. As shown in Figure 4, the coordinate system $\mathrm{O} x y$ is drawn at the left side of drawing board $\mathrm{E}_{1} \mathrm{E}_{2}$ with axis $\mathrm{Ox}^{+}$and $\mathrm{O}_{11} \mathrm{O}_{12}$ overlap. The relationship between the wheel discs and gears is same as that of pulley position and drawing curve $f(x)=\tan x,(0 \leq x<\pi / 2)$. The longitudinal poles $\mathrm{L}_{31} \mathrm{~L}_{32}$ and $\mathrm{L}_{41} \mathrm{~L}_{42}$ are fixed at the left points $\mathrm{B}_{1}$ and $\mathrm{B}_{2}$ of the wheel disc $\odot \mathrm{O}_{11}$ and $\odot \mathrm{O}_{12}$ respectively to make it tangent with the disc. The radial poles $\mathrm{O}_{11} \mathrm{Q}_{1}$ and $\mathrm{O}_{12} \mathrm{Q}_{2}$ are respectively fixed at the radius $\mathrm{O}_{11} \mathrm{C}_{1}$ and $\mathrm{O}_{12} \mathrm{C}_{2}$ of wheel discs $\odot \mathrm{O}_{11}$ and $\odot \mathrm{O}_{12}$ with the sliders $\mathrm{K}_{12}$ and $\mathrm{K}_{22}$ connecting with the left end of pole $\mathrm{L}_{11} \mathrm{~L}_{12}$ through shaft $\mathrm{T}_{1}$, the slider $\mathrm{K}_{13}$ and $\mathrm{K}_{23}$ connecting with the right end of pole $\mathrm{L}_{11} \mathrm{~L}_{12}$ through shaft $\mathrm{T}_{2}$, and the slider $\mathrm{K}_{11}$ connecting with $\mathrm{K}_{21}$ through the shaft $\mathrm{T}$. The top of the link $S_{1} A_{1} O_{12} X_{12}$ is fixed at cylinder $\mathrm{S}_{1}$ of $\odot \mathrm{O}_{11}$ and its end is fixed at $\mathrm{X}_{12}$ of pole $\mathrm{H}_{1} \mathrm{H}_{2}$ through pulley $\odot \mathrm{O}_{32}$ (initial point $\mathrm{A}_{1}$ ) bypassing a shaft $\mathrm{O}_{2} \mathrm{z}$. Adjusting the wheel discs $\odot \mathrm{O}_{1}$ and $\odot \mathrm{O}_{2}$ is to make the points of $S_{1}$ and $S_{2}$ respectively coincide with the initial ones $A_{1}$ and $A_{2}$ with longitudinal pole $\mathrm{L}_{31} \mathrm{~L}_{32}$ and $\mathrm{L}_{41} \mathrm{~L}_{42}$ almost vertical to $\mathrm{O}_{11}$ and $\mathrm{O}_{12}$ with pole $\mathrm{L}_{11} \mathrm{~L}_{12}$ at the top of the model. The pole $\mathrm{H}_{1} \mathrm{H}_{2}$ almost overlaps the shaft ${ }^{\mathrm{O} y}$ of $\mathrm{E}_{1} \mathrm{E}_{2}$ so the top of brush $\mathrm{Y}$ is near axis ${ }^{\mathrm{O} y}$ at the highest level of the system model. By shaking the handle of driving wheel disc $\odot \mathrm{O}_{21}$ counterclockwise, the system operation process is same as drawing curve $f(x)=\tan x,(0 \leq x<\pi / 2)$. Eventually, the trace with brush $\mathrm{Y}$ to draw on the drawing board $\mathrm{E}_{1} \mathrm{E}_{2}$ is the image function $y=\cot x,(0 \leq x \leq \pi)$.

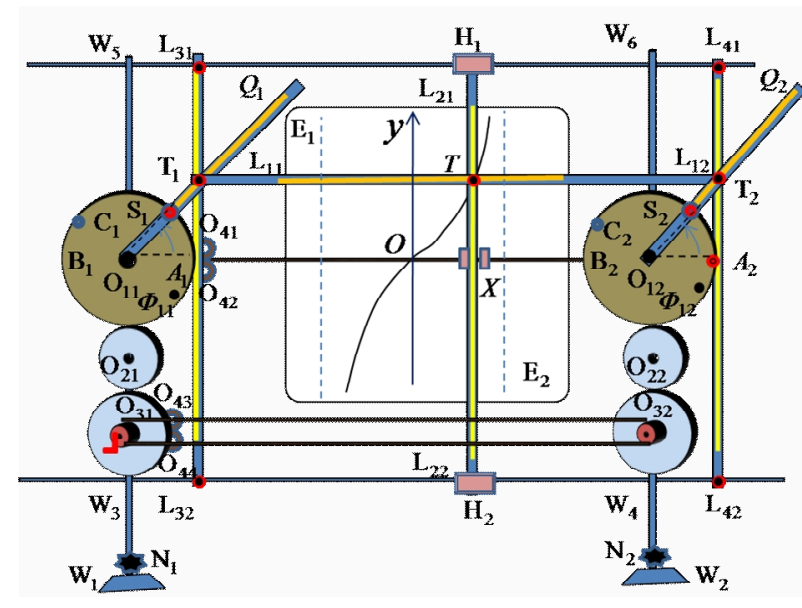

Fig.3. $y=\tan x$ images depicting the process.

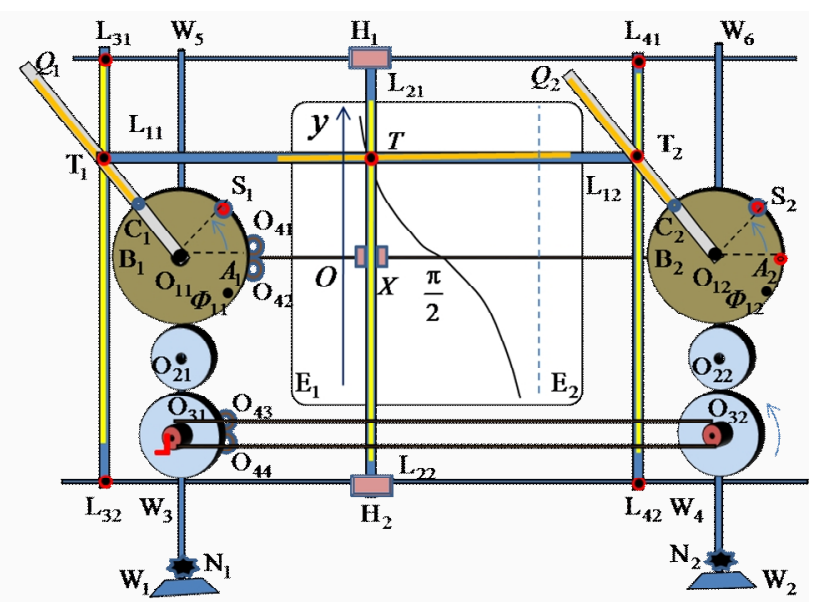

Fig.4. $y=\cot x$ images depicting the process

\section{Model application.}

System model image also can draw more complex function image, demonstrate and draw the image of tangent functions of such forms as the initial phase, variable period and amplitude. 
Description of image of function $y=a \cdot \tan x,(-\pi / 2<x<\pi / 2, a>0)$, System model under description of the initial state of the curve $f(x)=\tan x,(0 \leq x<\pi / 2)$ moves the longitudinal poles $\mathrm{L}_{31} \mathrm{~L}_{32}$ and $\mathrm{L}_{41} \mathrm{~L}_{42}$ to turn right or left at the same time, thus arriving at the points of $D_{1}$ and $D_{2}$ fixed respectively with $O_{11} D_{1}=O_{12} D_{2}=a R$. Other preparation and operation is exactly same as the description of curve $y=\tan x,(-\pi / 2<x<\pi / 2)$. Eventually, brush $\mathrm{Y}$ can draw the image of function $y=a \cdot \tan x,(-\pi / 2<x<\pi / 2, a>0)$ on the drawing board $\mathrm{E}_{1} \mathrm{E}_{2}$.

Description of image of function $y=\tan (x+\varphi),(-\pi / 2<x<\pi / 2, \varphi \neq 0)$. System model under description of the initial state of the curve $f(x)=\tan x,(0 \leq x<\pi / 2)$ adjusts the initial points $\mathrm{S}_{1}$ and $\mathrm{S}_{2}$ of the wheel disc $\odot \mathrm{O}_{1}$ and $\odot \mathrm{O}_{2}$. If $\varphi>0$, beginning with $\mathrm{O}_{11} \mathrm{~A}_{1}$ and $\mathrm{O}_{12} \mathrm{~A}_{2}$ respectively, discs $\odot \mathrm{O}_{11}$ and $\odot \mathrm{O}_{12}$ are rotated counterclockwise to make $\angle S_{1} \mathrm{O}_{11} A_{1}=\varphi$ and $\angle S_{2} \mathrm{O}_{12} A_{2}=\varphi$. If $\varphi<0$, beginning with $\mathrm{O}_{11} \mathrm{~A}_{1}$ and $\mathrm{O}_{12} \mathrm{~A}_{2}$, discs $\odot \mathrm{O}_{11}$ and $\odot \mathrm{O}_{12}$ are rotated clockwise to make $\angle A_{1} \mathrm{O}_{11} S_{1}=\angle A_{2} \mathrm{O}_{12} S_{2}=\varphi$. Other preparation and operating is exactly same as the description of curve $y=\tan x,(-\pi / 2<x<\pi / 2)$. Eventually, brush Y draws the image of function $y=\tan (x+\varphi),(-\pi / 2<x<\pi / 2, \varphi \neq 0)$ on the drawing board $\mathrm{E}_{1} \mathrm{E}_{2}$.

\section{Conclusion.}

In the commonly used traditional manual tracing, computer software drawing and automatic plotter drawing, automatic plotter is superior to others in process performance, image accuracy and convenience in use and so on. By plane circular motion, this paper expounds the expansion of the circular arc and displacement mapping principle, designs a dynamic demonstration tangent and cotangent function and draws the curve of the system model. Besides, structure of the model is introduced in detail with the specific analyses of the main parameters in the system and the description of the working principle of the system. In combination with different forms of function, the specific method about drawing image is given.

\section{Acknowledgements:}

The national natural science fund project (No, 11271194).

Nanjing Institute of Industry Technology science and technology innovation team project " dynamic demonstration and integration of image processing technology development research mathematical model of" (No, TK15-05-01)

\section{References}

[1]ShengJian Wu. Mathematical Analysis (Volume 2) Beijing: Peking University press,(2010)1-60

[2]Shuying Wang. Equivalent Conversion of Plane Figure, such as [J]. Journal of University Mathematics, (2007)173-179.

[3] Shuying Wang, Equivalent Conversion of Geometry [J]. Journal of Higher Mathematics Study,2007,73-79.

[4]He-ping xie, xiu-qian xue. Mathematics Foundation and Methods of Fractal Application. Beijing: Science Press, 1997.43-45.

[5] ZhuZhu Wu, Calculation Method. Beijing: tsinghua university press, 2010.1-60. 